\title{
Cultural Practices Shaping Zoonotic Diseases Surveillance: The Case of Highly Pathogenic Avian Influenza and Thailand Native Chicken Farmers
}

\author{
A. Delabouglise ${ }^{1,2}$, N. Antoine-Moussiaux ${ }^{1,3}$, D. Tatong ${ }^{4}$, A. Chumkaeo ${ }^{5}$, A. Binot ${ }^{1}$, G. Fournié ${ }^{6}$ \\ E. Pilot ${ }^{7}$, W. Phimpraphi ${ }^{8}$, S. Kasemsuwan ${ }^{8}$, M. C. Paul ${ }^{9}$, R. Duboz ${ }^{1,10}$, G. Salem ${ }^{2}$ and M. Peyre ${ }^{1,11}$ \\ ${ }^{1}$ AGIRs-Animal and Integrated Risk Management Research Unit, CIRAD-Agricultural Research Center for International Development, Montpellier, \\ France \\ 2 LADYSS - Enjeux Sanitaires et Territoires, CNRS, Paris Ouest University, Nanterre, France \\ 3 FARAH-Fundamental and Applied Research for Animals \& Health, University of Liège, Liège, Belgium \\ ${ }^{4}$ The 6th Regional Livestock Office, Phitsanulok, Thailand \\ ${ }^{5}$ Provincial Livestock Office, Satun, Thailand \\ ${ }^{6}$ Veterinary Epidemiology, Economics and Public Health Group, Department of Production and Population Health, Royal Veterinary College, \\ University of London, Hatfield, UK \\ 7 CAPHRI School of Public Health and Primary Care, Faculty of Health, Medicine and Life Sciences, Maastricht University, Maastricht, The Netherlands \\ 8 Faculty of Veterinary Medicine, Kasetsart University, Nakorn-pathom, Thailand \\ ${ }^{9}$ IAHP, Université de Toulouse, INRA, ENVT, Toulouse, France \\ ${ }_{10}$ Asian Institute of Technology, Pathumthani, Thailand \\ 11 National Institute of Veterinary Research, Hanoi, Viet Nam
}

\section{Keywords:}

H5N1 Highly Pathogenic Avian Influenza; mandatory reporting; network analysis; participatory epidemiology; passive surveillance; poultry production

\section{Correspondence:}

A. Delabouglise. The Royal Veterinary College, Hawkshead Lane, North Mymms, Hatfield, Hertfordshire, AL9 7TA, UK.

Tel.: +44 (0)1707 667020;

E-mail: alexis.delabouglise@gmail.com

Received for publication October 23, 2015

doi:10.1111/tbed.12506

\section{Summary}

Effectiveness of current passive zoonotic disease surveillance systems is limited by the under-reporting of disease outbreaks in the domestic animal population. Evaluating the acceptability of passive surveillance and its economic, social and cultural determinants appears a critical step for improving it. A participatory rural appraisal was implemented in a rural subdistrict of Thailand. Focus group interviews were used to identify sanitary risks perceived by native chicken farmers and describe the structure of their value chain. Qualitative individual interviews with a large diversity of actors enabled to identify perceived costs and benefits associated with the reporting of HPAI suspicions to sanitary authorities. Besides, flows of information on HPAI suspected cases were assessed using network analysis, based on data collected through individual questionnaires. Results show that the presence of cockfighting activities in the area negatively affected the willingness of all chicken farmers and other actors to report suspected HPAI cases. The high financial and affective value of fighting cocks contradicted the HPAI control policy based on mass culling. However, the importance of product quality in the native chicken meat value chain and the free veterinary services and products delivered by veterinary officers had a positive impact on suspected case reporting. Besides, cockfighting practitioners had a significantly higher centrality than other actors in the information network and they facilitated the spatial diffusion of information. Social ties built in cockfighting activities and the shared purpose of protecting valuable cocks were at the basis of the diffusion of information and the informal collective management of diseases. Building bridges with this informal network would greatly improve the effectiveness of passive surveillance. 


\section{Introduction}

Passive animal health surveillance is a central issue for countries facing threats of emerging or zoonotic diseases (Bonfoh et al., 2010). It generally relies on the voluntary report of sanitary events by animal owners. However, the acceptability of such surveillance system has been subject to limited attention. Acceptability refers to the willingness of local actors, which may be private (e.g. animal owners) or public (e.g. veterinary officers) to report information to the authorities in charge of animal disease control (Hoinville, 2011). It depends on the anticipated benefits and costs related to the reporting of a suspected sanitary event, from the point of view of the local actors (Chilonda and Van Huylenbroeck, 2001; Elbers et al., 2010b). Meanwhile, informal disease information sharing networks might emerge and provide support to farmers, therefore possibly competing with the official surveillance (Hickler, 2007; Desvaux and Figuie, 2011).

Highly pathogenic avian influenza (HPAI) subtype H5N1 attracted significant attention since its emergence in 1996 and global expansion in 2003-2006 (Scoones and Forster, 2008).

Thailand was affected by several HPAI H5N1 epizootics from 2004 to 2009. Thailand incurred 12 human deaths (World Health Organization, 2014) and severe economic losses, mainly due to trade bans enforced on exported Thai poultry products and decrease of tourism (Heft-Neal et al., 2009b; Rushton et al., 2005). The HPAI crisis highlighted the need for better surveillance and rapid response systems to tackle outbreaks faster (Safman, 2009; Auewarakul et al., 2008). Thailand has been officially HPAI free since 2009 (FAO, 2014). However, HPAI is still occurring in several surrounding countries including China, Cambodia and Vietnam, putting Thailand at risk of re-infection. Early detection of any potential reintroduction of the $\mathrm{H} 5 \mathrm{~N} 1$ virus is of major importance for Thailand, both in terms of public health and economic performance of the poultry industry.

Following HPAI, the number of small-scale poultry farms decreased, and today, poultry products in Thailand come mostly from a limited number of integrated settings managed by private agro-industrial companies (Heft-Neal et al., 2008). Nevertheless backyard chicken farms, specialized in native chicken breeds, are still widespread, in particular in rural areas, and still represent the majority of the poultry flocks (Heft-Neal et al., 2008). Backyard native chicken farming is mainly practiced for home consumption of chickens, sale of chicken meat and cockfighting. Backyard chicken farms and their associated value chain are vulnerable to contagious diseases due to their limited biosecurity level (Paul et al., 2011, 2013; Walker et al., 2012). There is a special need to take this sector into account by designing adequate surveillance strategies to protect poultry industry and human health (Heft-Neal et al., 2009a). According to the current Thai regulation, poultry owners must report to the competent veterinary authorities any sanitary event matching the HPAI clinical case definition (Government of Thailand, 2007).

In this study, we aimed at documenting the two following questions: which costs and benefits associated with HPAI suspected case reporting to veterinary authorities are anticipated by local actors? Are there any informal sharing of disease suspicion information outside the scope of veterinary authorities, and which actors are involved in it?

\section{Materials and Methods}

A mixed methodology was applied. First, a survey using methods of participatory epidemiology (PE) was conducted (Catley et al., 2012), aimed at identifying perceived costs and benefits associated with HPAI suspicion reporting. Secondly, a questionnaire survey aimed at describing and analysing the network of information sharing on suspicions among native chicken farmers (Jackson, 2008).

\section{Study area}

With the help of the National Department of Livestock Development of Thailand, the rural subdistrict of Krai Nok, Kong Krailat district, Sukhothai province (North Thailand), was selected for the study. The subdistrict combined the presence of numerous native chicken farms with diversity of other production systems (including commercial broiler chicken farms) and spatial risk factors for HPAI occurrence (presence of free-grazing ducks and rice paddy fields) (Gilbert et al., 2007; Paul et al., 2010). The entire study was conducted from February to May 2013.

\section{Qualitative interviews: analysing costs and benefits associated with HPAI suspicion reporting}

\section{Sampling}

The sampling strategy followed a snowball sampling pattern (Sadler et al., 2010). Poultry farmers were targeted first. Three focus group interviews with native chicken farmers were conducted in 3 villages of the study subdistrict. Chicken farmers were contacted with the help of the District Livestock Department, as well as subdistrict and village authorities. Poultry farmers who displayed interest in further participating in the study were then asked for individual interviews. The number of these individual interviews was determined by adapting the concept of saturation to the objective of the study (Bowen, 2008). Saturation was considered to be reached when 10 additional 
interviews did not provide any new information on anticipated costs and benefits compared with all previous interviews. In individual interviews, other categories of actors were identified as being directly or indirectly impacted by the avian diseases surveillance system. Individuals belonging to those additional categories of actors and in contact with individuals from the initial sampling frame were asked to participate in the study. Those who accepted were individually interviewed. Additionally, individual interviews of village heads, members of the subdistrict government and veterinary officers at the subdistrict, district and province levels were performed.

\section{Data collection}

Interviews were conducted using methods of PE (Catley et al., 2012). Semi-structured interviews were performed using a checklist of pre-defined topics. Data were collected by teams of 1 or 2 researchers with the help of a translator. All the interviews were conducted in Thai language. Focus group interviews were conducted in village communal houses. Individual interviews were conducted in the private houses or workplaces of participants. Field notes were used to record the contents of interviews.

Topics of focus group interviews were as follows: (i) identification of actors potentially involved in the native chicken value chain (sources of household income and credit, origin of feed, breeds and medicines, use of farm products); (ii) names used locally for poultry diseases occurring in the area. Diseases were attributed a score according to their impact on income, rates of mortality and duration using proportional piling (Catley et al., 2012). Reported names of disease characterized by both high mortality rate ( $>50 \%$ in one poultry flock) and short duration ( $<5$ days in one flock) were used to define HPAI suspicions which were referred to in subsequent interviews. Topics of individual interviews were as follows: (i) relative importance of personal incentives and disincentives linked to the reporting of disease suspicions to veterinary authorities; (ii) identification of actors impacted by disease suspicion reporting, which were assigned different signs and colours to indicate whether the effect was perceived as positive or negative. In any cases, general and opened questions were used to let the participant focus on what seemed relevant for them, preventing a priori knowledge of the interviewer from influencing the responses.

\section{Data analysis}

Qualitative data were analysed using thematic analysis (Graneheim and Lundman, 2004). Meaning units, that is information or judgments expressed in interviews, were attributed specific codes. Codes were then grouped into subthemes and themes. Identified themes corresponded to specific factors influencing the willingness of participants to report HPAI suspicions to the public surveillance system, either positively or negatively.

\section{Questionnaire survey: information-sharing networks}

A questionnaire survey including close-ended and openended questions was implemented to identify and analyse the information flows related to poultry diseases suspicions among native chicken farmers.

\section{Sampling}

The sampling was independent from the sampling of the survey presented before. Four adjacent villages of the study subdistrict were included in the survey. The selection of interviewed native chicken farmers was performed through several transect walks in the 4 villages.

\section{Data collection}

Data were collected by teams of one researcher and one translator. Each participant was individually interviewed, using a questionnaire which was filled by one member of the research team. They were asked about details of their own chicken farming practice: flock size, sale of chickens for meat, sale of cocks for fighting, breeding of the birds, participation of their cocks to fighting games. They were also asked about their main occupation and administrative role (if any). Then, they were asked to identify the people they would inform in case of (i) a disease suspicion in their flocks and (ii) a disease suspicion in someone else's flock. Finally, they were asked to detail their relation with the contacted person and to indicate whether this person raised poultry and, if so, which type (chicken/duck, commercial/ backyard/cockfighting), the main occupation of the contacted person and his administrative role (if any).

\section{Data analysis}

All data computing and analyses were performed using R.3.0.3 (R core team, 2014). Observed networks were directed and unweighted. Nodes were the interviewed native chicken farmers and individuals mentioned in questionnaires. Links were information flows. Two types of links were recorded, and therefore, two different networks were observed: (i) transmission of information by a given poultry farmer on disease suspicions happening in his farm (primary information) and (ii) transmission of information from a given actor on disease suspicions happening in other farms (secondary information). Bonacich's alpha centrality measure was used as an indicator of the quantity of information each actor could obtain when an HPAI suspicion occurred (Bonacich and Lloyd, 2001). Using this indicator enables to account for the two types of links mentioned above. The alpha centralities correspond to the solution to the following matrix equation: 


$$
x=\alpha \cdot A^{T} \cdot x+e
$$

where $A^{T}$ is the transpose of the adjacency matrix $A$ which only accounts for secondary exchanges. $x$ is the vector of alpha centralities of the network's nodes; $e$ is the vector of exogenous influences on nodes of the network that do not depend on the structure of the network; and $\alpha$ is a parameter that corresponds to the relative importance of the network topology. It was assumed that each node $i$ had exogenous sources of information ei that directly came from owners of affected farms. In other words, each value $e i$ was the indegree of the node $i$ when only primary information delivered by affected farms was considered. The considered links of the network were the secondary information exchanges. Therefore, the higher the value of $\alpha$ the higher the contribution of secondary information exchanges to the centrality of each node. The value of $\alpha$ was chosen to be as high as possible while satisfying $\alpha<1 / \lambda$, $\lambda$ being the highest eigenvalue of the adjacency matrix. Two different values of $\alpha$ were used: $\alpha=0$ (accounting only for primary exchanges) and $\alpha=0.3$ (accounting for both primary and secondary exchanges). The igraph package was used to calculate alpha centrality measures (Csardi and Nepusz, 2006).

The association between alpha centrality measures (continuous-dependent variable) and several attributes of interviewed native chicken farmers was assessed using multivariate linear regression. The tested attributes were the village and several farming attributes: flock size, breeding, sale of fighting cocks, sale of chickens for meat and participation of the interviewee's cocks in fighting games. Variables to include in the model were first tested individually by simple linear regression. Only variables whose test returned $P$ values $P<0.25$ were included in the complete model. Pre-selected variables and associated interaction terms were integrated in the complete model. The best-fitting model was selected using stepwise selection based on Aikaike's information criteria (AIC), with 'MASS' R package (Venables and Ripley, 2002).

Given that the assumption of independency between observations was not verified (each individuals' alpha centrality is determined by the alpha centrality of the others), $P$-values were computed based on permutations (Ryu et al., 2013), using 'ape' R package (Paradis et al., 2004): linear regressions were performed for each of 100000 permutations of the original sample of observed alpha centrality measures. Displayed $\mathrm{p}$ values were the proportions of $\mathrm{p}$ values obtained with the permuted samples which were lower than the p-value computed with the observed sample (Anderson and Legendre, 1999).

Second, the association between interviewees' attributes and occurrence of information transmission was assessed using multivariate logistic regression on networks with 'sna' R package (Butts, 2010). Transmissions of any types of information (about one's farm or another farm) were considered. Four link attributes were assessed: the Euclidean distance between interviewees and three qualitative link attributes ('Sender and receiver belong to the same village', 'Sender participates in cockfighting games' and 'Receiver participates in cockfighting games'). The best-fitting model was selected on the basis on its AIC. $P$-values were computed based on 100000 permutation of the observed network adjacency matrix using a semi-partialling quadratic assignment procedure (QAP) (Dekker et al., 2003). Area under the curve (AUC) of the resulting receiver operating characteristics (ROC) was calculated using 'AUC' R package (Ballings and Van den Poel, 2013).

\section{Ethics}

Informed consent was obtained orally from all participants involved in both surveys. Interviewees were always informed of the purpose of the study and could stop the interview whenever they wanted. Names and contact details of interviewees were kept in a secured database only accessible to the research team.

\section{Results}

Native chicken value chain and sanitary problems perceived by native chicken farmers

Native chicken farmers from villages 1, 3 and 8 participated in 3 focus group discussions comprising, respectively, 11, 14 and 10 participants. The flows of inputs and outputs of native chicken farms are presented in Fig. 1. Chickens were raised for home consumption, local sale to villagers, sale to collectors for meat production, participation in cockfighting or sale to cockfighting practitioners or fighting cock traders. Native chicken flock sizes ranged from 10 to 100 animals. Reproduction relied mainly on self-renewal of flocks, and new breeds were imported from other native chicken farms: farmers occasionally lent their own hens to others chicken owners for reproduction purpose. Cockfighting was practiced in illegal arenas. One arena was present in one of the villages of the study area. Cockfighting practitioners gathered in teams to make their best cocks participate in games and to combine their money for gambling.

Epizootics causing high mortality were said to happen regularly in the area. Table 1 summarizes the names of diseases mentioned by poultry farmers. These names only refer to poultry farmer's perception and do not constitute a diagnosis. Bird flu was mentioned as a past disease. The names 'Newcastle' (Newcastle Disease), 'Diarrhoea' (interpreted as 'Fowl cholera') and 'Plague' (a general word used to qualify a rapid and massive mortality) were used to describe sanitary events of main concern for native chicken farmers. The Thai word 'Ha' ('Plague') was then used to 
Fig. 1. Description of the native chickens value chain in the study area. Black arrows refer to flows of inputs and outputs of native chicken farms.

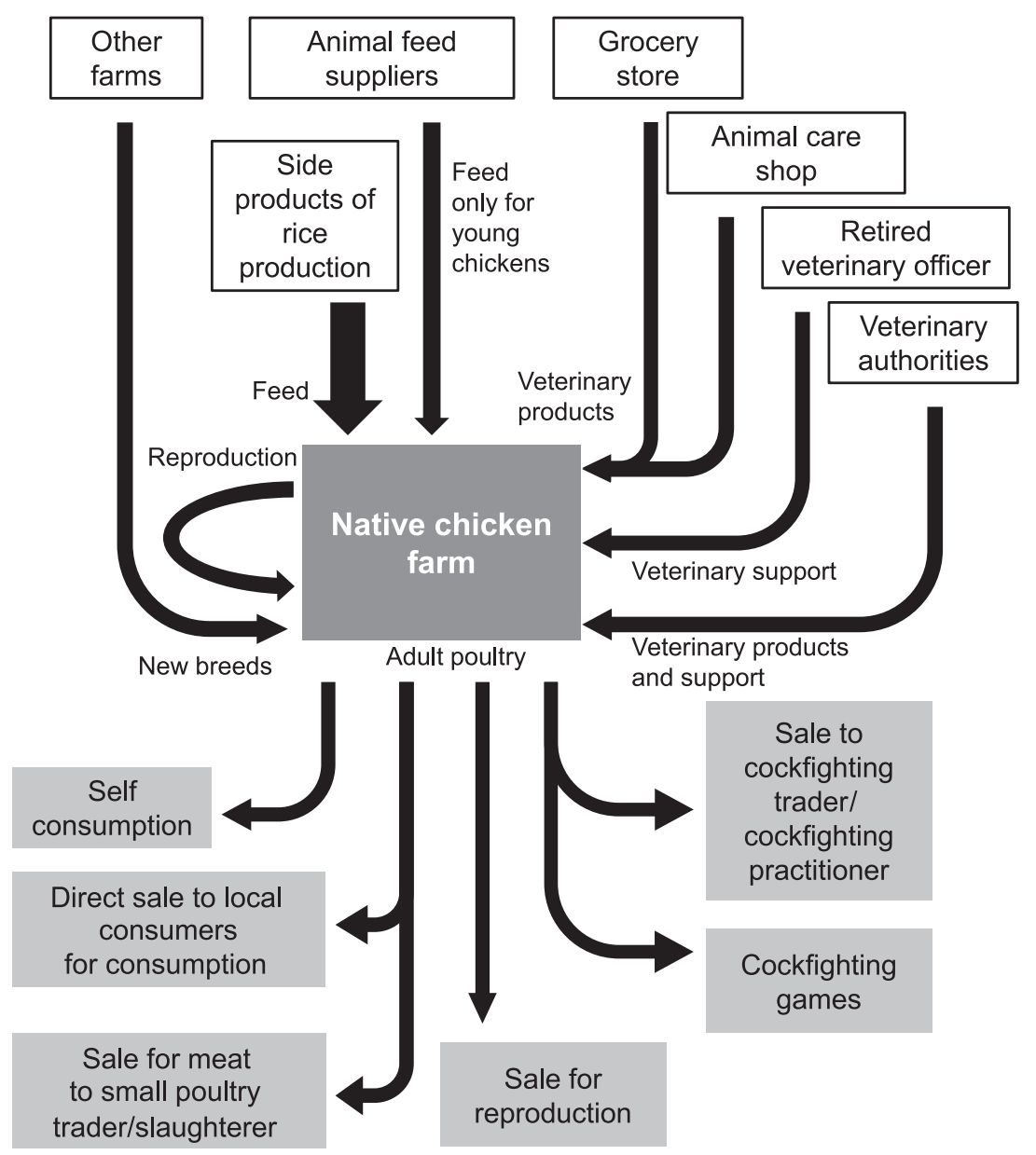

Table 1. Chicken disease characterization by farmers of the study area. Disease names only refer to native chicken farmer's perception and should not be considered as an accurate diagnosis

\begin{tabular}{llllll}
\hline Thai name & Pronunciation & English translation & Interpretation & Description & Affected villages \\
\hline อหิวาต์ & Ah-He-Wa & Diarrhoea & Fowl cholera & Low duration, high rate of mortality & $1,3,8$ \\
ห่า & $\mathrm{Ha}$ & Plague & Unknown & Rate of mortality near to 100\% & $1,3,8$ \\
นิวคาสเซิล & Newcastle & Newcastle & Newcastlea & Low duration, high rate of mortality & $1,3,8$ \\
หวัดนก & Whaat-Nok & Bird Flu & HPAlb & Very low duration, high rate of mortality & 3 \\
ฝีดาษ & Fhee-Daat & Small pox & Fowl pox & Limited impact Only affects young chickens & 3 \\
หวัดหน้าบวม & Whaat-Nha-Buam & Swollen face flu & Infectious coryza & High rate of mortality but can be treated & 3,8 \\
\hline
\end{tabular}

aThailand is officially free from Newcastle disease, but the term was used by chicken farmers.

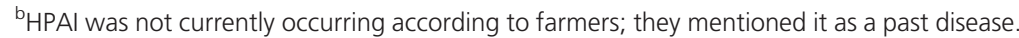

refer to disease suspicions in subsequent interviews, including the questionnaire survey for network analysis.

\section{Perceived costs and benefits associated with disease reporting}

Sample characteristics

A total of 50 participants were involved in individual qualitative interviews. The sample included native chicken farm- ers $(n=26)$, chicken collectors $(n=4)$, sellers of medicine products for chickens $(n=4)$, the manager of a cockfighting arena $(n=1)$, Buddhist monks $(n=2)$, health volunteers $(n=4)$, heads of governments of the subdistrict $(n=2)$ and villages $(n=2)$, subdistrict veterinary officers $(n=1)$, district veterinary officers $(n=2)$ and province veterinary officers $(n=2)$. Several interviews were performed with actors who were based outside of Krai Nok subdistrict, but who operated in that subdistrict: livestock 
officers $(n=4)$, veterinary medicine sellers $(n=3)$ and chicken collectors $(n=3) .44 .6 \%$ of native chicken farmers who were originally inquired refused to take part in individual interviews. All individuals of the other categories accepted except one village head. Identified costs and benefits associated with poultry disease surveillance are presented in Table 2.

\section{Benefits}

According to native chicken farmers, veterinary authorities could provide a free veterinary support to farmers (supply of veterinary products, advices, help in disease management) following a report (Fig. 1). Apart from HPAI suspected cases, such support was said to be provided for other diseases, such as so-called 'Newcastle' and 'Fowl cholera', which made it even more attractive. This veterinary support was perceived as a benefit of the passive poultry disease surveillance.
According to participants, chicken flocks declared infected of HPAI had to be destroyed. Indemnities which were provided to compensate culled animals ranged between 20 and 100 THB (0.56-2.24 USD)/animal while native chickens sold for meat consumption were bought by collectors at 70-80 THB (1.96-2.24 USD)/kg. Indemnities were therefore considered interesting from the standpoint of farmers raising chickens primarily for meat production. Diseased animals were said not to be marketable, making state indemnities the only expectable mean of financial profit when faced with high mortality diseases like HPAI suspected cases. Chickens sold for meat were bought by local collectors who sold it in wet markets or to specific customers such as restaurants or slaughterers. Poultry farmers as well as collectors said the sale of diseased or dead animals was difficult because their customers carefully chose their products based on their appearance. Native chicken meat was considered a quality product, with particular taste qualities, and customers were exigent on the good appearance of the meat.

Table 2. Perceived costs and benefits associated with suspicion reporting. Costs and benefits of HPAl suspicion reporting to authorities correspond to themes extracted from participants' interviews

\begin{tabular}{|c|c|c|c|c|}
\hline & Nature of cost/benefits & & Explanation & Quotation \\
\hline \multirow[t]{5}{*}{ COSTS } & \multirow[t]{4}{*}{$\begin{array}{l}\text { Costs anticipated by } \\
\text { native chicken farmers }\end{array}$} & Monetary cost & $\begin{array}{l}\text { The monetary value of one } \\
\text { healthy cock can largely excess } \\
\text { the indemnity amount }\end{array}$ & $\begin{array}{l}\text { 'People will get compensation but really, it is not } \\
\text { worth getting it. Fighting cocks are much more } \\
\text { valuable. They give maximum } 100 \text { baht per animal. } \\
\text { Fighting cocks can have a value of several } \\
\text { thousands'. (a native chicken farmer) }\end{array}$ \\
\hline & & Loss of breeds & $\begin{array}{l}\text { Loss of selected breeds of cocks } \\
\text { aimed at fighting }\end{array}$ & $\begin{array}{l}\text { 'We cannot earn much money with cockfighting; it } \\
\text { is the preservation of our breeds that matters'. (a } \\
\text { native chicken farmer) }\end{array}$ \\
\hline & & Emotional impact & $\begin{array}{l}\text { The emotional link between the } \\
\text { farmer and his cocks }\end{array}$ & $\begin{array}{l}\text { 'For me my cocks are like my children, they belong } \\
\text { to my family'. (a native chicken farmer) } \\
\text { 'We like our cocks. If one likes his cock, he doesn't } \\
\text { want him to be killed'. (a native chicken farmer) }\end{array}$ \\
\hline & & $\sin$ & $\begin{array}{l}\text { The culling of healthy animals out } \\
\text { of purpose of consumption }\end{array}$ & $\begin{array}{l}\text { 'the cock has a heart like us. According to Buddhism } \\
\text { it is a sin to kill an animal in this way'. (a native } \\
\text { chicken farmer) }\end{array}$ \\
\hline & \multicolumn{2}{|c|}{ Costs anticipated by all actors } & $\begin{array}{l}\text { Anticipated impact on farmers of } \\
\text { the area. It is perceived as a } \\
\text { source of conflicts between } \\
\text { people reporting to veterinary } \\
\text { services and chicken farmers } \\
\text { potentially affected by the } \\
\text { control measures }\end{array}$ & $\begin{array}{l}\text { 'Farmers who are not affected would blame the } \\
\text { affected farmer for reporting to veterinary } \\
\text { authorities'. (a native chicken farmer) } \\
\text { 'I cannot report because I would cause a conflict } \\
\text { with the people who have healthy chickens. They } \\
\text { would insult me'. (a health volunteer) } \\
\text { 'Farmers are reluctant to report to veterinary } \\
\text { authorities because they are afraid of the fighting } \\
\text { cock farmers'. (a veterinary officer) }\end{array}$ \\
\hline \multirow[t]{2}{*}{ BENEFITS } & \multicolumn{2}{|l|}{ Sanitary support } & $\begin{array}{l}\text { Veterinary services provided } \\
\text { veterinary products for free in } \\
\text { response to a reported disease } \\
\text { suspicion }\end{array}$ & $\begin{array}{l}\text { 'if you report regularly about the incidence of } \\
\text { diseases all along the year, you can ask medicines } \\
\text { to the chief of village and she asks the veterinary } \\
\text { authorities'. (a native chicken farmer) }\end{array}$ \\
\hline & \multicolumn{2}{|l|}{ Financial indemnities } & $\begin{array}{l}\text { Financial indemnities ware } \\
\text { attributed in compensation of } \\
\text { the destruction of flocks }\end{array}$ & $\begin{array}{l}\text { 'I report if there is compensation, if there is no } \\
\text { compensation I don't. I need to make sure I will get } \\
\text { the money'. (a native chicken farmer) }\end{array}$ \\
\hline
\end{tabular}




\section{Costs}

Financial costs were associated with preventive culling. Participants were concerned chicken flocks in the $3 \mathrm{~km}$ radius area around the HPAI-infected farms could potentially be destroyed by authorities to prevent disease propagation. Even if, according to the new law, the 3-km-radius mass culling was not compulsory anymore, native chicken farmers still perceived such policy could be implemented again. This financial impact was small for farmers raising chickens primarily for meat production given the low sale price of chickens. However, cocks bred and trained for fighting had a much higher financial value. They could be sold to cockfighting practitioners at prices ranging from 200 to 1000 THB (5.6-28.0 USD)/cock. Cocks with a high record of victories could be sold at a price ranging from 5000 to 50000 THB (140-1400 USD) in provincial arenas. The highest price reached so far was $150000 \mathrm{THB}$ (4205 USD) for one cock.

Nevertheless, profits from all types of native chickens farming activities represented a minor share in the overall households' incomes. Interviewed chicken farmers always mentioned other activities (mostly rice production) as their main source of income, and, according to authorities, native chicken farming did not significantly contribute to the population's income. Financial considerations, therefore, played a limited part in farmer's decision.

However, participants perceived impacts of non-financial nature (Table 2). Farmers breeding cocks destined at cockfighting anticipated several costs associated with reporting, closely linked to their memory of past HPAI epizootics and resulting preventive mass culling:

1 The loss of breeds resulting from efforts invested by the farmer in long-lasting selection and cross-breeding.

2 The emotional impact of chicken culling related to the affection of chicken farmers for their animals. This emotional attachment was expressed through the terminology used: Thai words meaning 'sympathy', 'pity', 'love', 'mercy' were employed by participants.

3 The moral fault associated with the culling of chickens. Participants mentioned that culling a healthy animal out of consumption purpose was considered morally objectionable, according to Thai Buddhist religious values. This observation was confirmed through discussions with the two Buddhist monks living in the study subdistrict.

Farmers raising their chickens for cockfighting were hostile to reporting for all abovementioned reasons. On the contrary, farmers raising their chickens mainly for meat production were keen on reporting suspicions in order to receive support from veterinary authorities and actors of the official HPAI surveillance, that is village heads and health volunteers were willing to report out of duty. The two latter categories expressed a concern about the impact their reporting decision could have on cockfighting farmers. In the village where the cockfighting arena was located, a particular antagonism was mentioned between health volunteers, who reported HPAI suspicions in the past, and cockfighting practitioners.

\section{Results of Network Analysis}

In total, 30 questionnaire-based interviews were performed with native chicken farmers located in 4 different villages of Krai Nok subdistrict. $35.7 \%$ of native chicken farmers who were originally inquired refused to take participate in interviews. Raising cocks for fighting was a very common activity among them $(n=26)$. Nineteen interviewees engaged their own cocks in games organized in the arenas. They are hereafter mentioned as 'cockfighting practitioners'. Measures of alpha centralities along with location of interviewees are presented in Fig. 2. The following observations were made:

1 Information exchanges were mainly made with persons considered as relatives (52.6\%), friends $(26.0 \%)$ and neighbours (16.5\%). 28.0\% of information flows targeted fighting cocks owners and $89.0 \%$ of information flows from one village to another village targeted fighting cock owners. Actors mentioned in focus group interviews as source of veterinary products or veterinary support (Fig. 1) were scarcely mentioned as contacts in case of disease suspicion.

2 The most common motivation for information exchange was to warn the receiver $(60.4 \%)$. The purpose of warning was to protect the targeted farmer by different means: avoiding contacts with other cocks of the area, stopping cockfight trainings and games, vaccinating the animals and moving the animals outside the area. Another mentioned purpose was simply informing about the case in casual discussion (16.5\%), getting support in diagnosis, treatment of sick birds or disposal of carcasses $(4.6 \%)$ and, for cockfighting practitioners, to check the health of the cocks they had lent to other farmers for reproduction (5.9\%). Declaring the disease to authorities was the purpose of only $1.7 \%$ of information flows, either by informing village heads or public health volunteers. However, the village head of one of the villages and the veterinary officer of the subdistrict had high alpha centrality measures. They were both cockfighting practitioners.

Results of multivariate linear regressions on alpha centrality measures are presented in Table 3. For $\alpha=0$, the best-fitting model included participation in cockfighting games, which was the only variable significantly associated with alpha centrality (at 95\% significance level). For $\alpha=0.3$, variables included in the best-fitting model that 


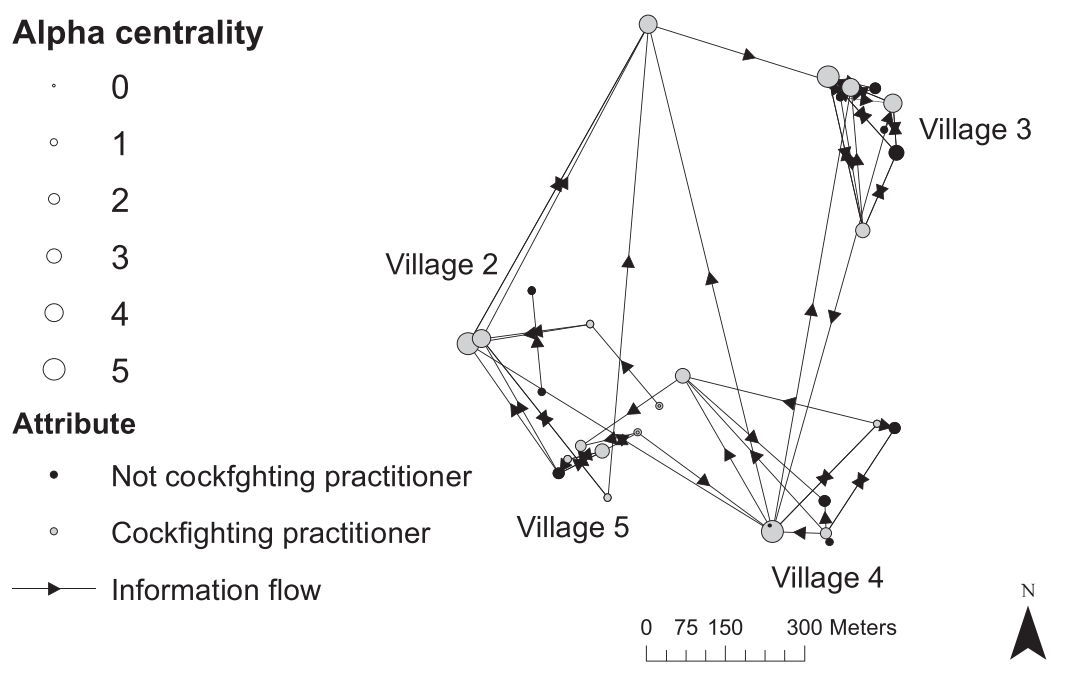

\section{Alpha centrality}

- $0-5$

○ $5-10$

○ $10-15$

○ $15-20$

$20-25$

$25-30$

\section{Attribute}

- $\quad$ Not cockfghting practitioner

- Cockfighting practitioner

$\longrightarrow$ Information flow

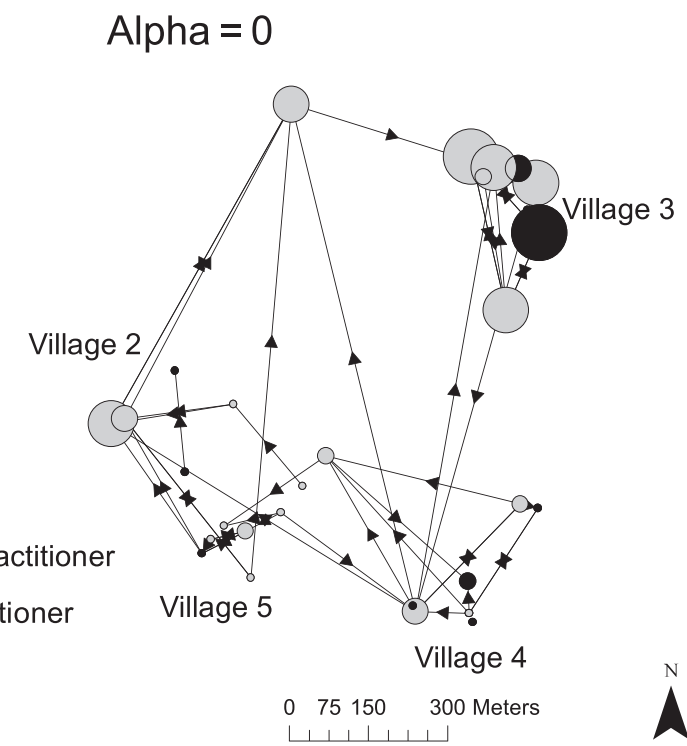

Alpha $=0.3$
Fig. 2. Observed network of information flows and resulting centralities. Circles represent spatially localized interviewed native chicken farmers. Arrows represent identified flows of information, and sizes of circles are in proportion with alpha centralities, for two different values of $\alpha$ : $\alpha=0$ (up) and $\alpha=0.3$ (down). Colours of circles indicate whether interviewees practice cockfighting (grey colour) or no (black colour). were significantly associated with alpha centrality were participation in cockfighting games and village (at 95\% significance level). The adjusted coefficient of determination $R^{2}$ was higher for the second model $(\alpha=0.3)\left(R^{2}=0.60\right)$ compared with the first $(\alpha=0)\left(R^{2}=0.33\right)$.

Results of the multivariate network logistic regression are presented in Table 4. The model with the lowest AIC included as explanatory variables: Euclidean distance between nodes, link attribute 'presence of the sender and receiver in the same village', interaction term between Euclidean distance and participation of source in cockfighting games and interaction term between Euclidean distance and participation of target in cockfighting games. These four variables were significantly associated with link occurrence (at 99\% significance level). Links were much more likely to occur between individuals of the same village $(\mathrm{OR}=9.573)$ and probability of link occurrence decreased with Euclidean distance $(\mathrm{IOR}=0.437 / \mathrm{km})$. This effect of distance was significantly reduced in case the source or the target was a cockfighting practitioner, as shown by the significant interaction terms. The AUC of the ROC curve of the logistic model was equal to 0.86 , showing that the model had acceptable to excellent discrimination performance (Hosmer and Lemeshow, 2000).

\section{Discussion}

The main limit of the study is its limited geographical scale. Perception of sanitary risks and their management are strongly influenced by the local context and cannot be anal- 
Table 3. Results of the linear regressions. Regressions were performed on measures of alpha centralities associated with interviewed farmers

\begin{tabular}{|c|c|c|c|c|c|c|}
\hline$\alpha$ & Attribute & Level & $n$ & Estimated coefficient & $P^{*}$ & $R^{2}$ \\
\hline \multirow[t]{6}{*}{$\alpha=0$} & \multirow[t]{4}{*}{ Village } & Village 3 & 8 & 0 & & $R^{2}=0.33$ \\
\hline & & Village 2 & & -0.516 & 0.523 & $F$-test* \\
\hline & & Village 4 & 10 & -1.410 & 0.055 & $P<0.05$ \\
\hline & & Village 5 & 6 & -1.783 & 0.039 & \\
\hline & \multirow{2}{*}{$\begin{array}{l}\text { Cockfighting } \\
\text { practitioner }\end{array}$} & No & 11 & 0 & & \\
\hline & & Yes & 19 & 1.599 & 0.011 & \\
\hline \multirow[t]{6}{*}{$\alpha=0.3$} & \multirow[t]{4}{*}{ Village } & Village 3 & 8 & 0 & & $R^{2}=0.60$ \\
\hline & & Village 2 & 6 & -10.479 & $<0.01$ & $F$-test* \\
\hline & & Village 4 & 10 & -15.050 & $<0.01$ & $P<0.05$ \\
\hline & & Village 5 & 6 & -17.331 & $<0.01$ & \\
\hline & \multirow{2}{*}{$\begin{array}{l}\text { Cockfighting } \\
\text { practitioner }\end{array}$} & No & 11 & 0 & & \\
\hline & & Yes & 19 & 7.310 & $<0.01$ & \\
\hline
\end{tabular}

* $P$ values of permutation tests (100 000 iterations).
Table 4. Results of the logistic regression. The regression was performed on the network of information flows of interviewed farmers

\begin{tabular}{|c|c|c|c|c|}
\hline Attribute & Level & na & $\begin{array}{l}\text { Odds } \\
\text { ratio }\end{array}$ & $P^{*}$ \\
\hline $\begin{array}{l}\text { Euclidean distance } \\
\text { (One unit corresponds } \\
\text { to } 100 \mathrm{~m} \text { ) }\end{array}$ & & & $0.437 b$ & $<0.01$ \\
\hline \multirow[t]{2}{*}{ Same village } & No & 694 & 1 & \\
\hline & Yes & 206 & 9.628 & $<0.01$ \\
\hline Source is & No & 349 & 1 & \\
\hline cockfighting practitioner & Yes & 551 & 1.100 & 0.896 \\
\hline Target is & No & 349 & 1 & \\
\hline cockfighting practitioner & Yes & 551 & 1.121 & 0.864 \\
\hline $\begin{array}{l}\text { Interaction } \\
\text { Source is cockfighting } \\
\text { practitioner - Euclidean } \\
\text { distance }\end{array}$ & & & $1.345 b$ & $<0.01$ \\
\hline $\begin{array}{l}\text { Interaction } \\
\text { Target is cockfighting } \\
\text { practitioner - Euclidean } \\
\text { distance }\end{array}$ & & & $1.642 b$ & $<0.01$ \\
\hline
\end{tabular}

${ }^{a} n$ figures correspond to numbers of links.

bincremental odds ratio.

* $P$ values of permutation tests (100 000 iterations).

ysed apart from the understanding of economic, social and cultural factors of specific places. This constraint justifies the limitation of the study to a restricted area. However, attributes of the native chicken production sector which were found to influence the perception of surveillance systems and the constitution of information networks (i.e. presence of cockfighting activities, quality-orientated native chicken value chain) were found to be widespread in Thailand (Heft-Neal et al., 2009a; Paul et al., 2011).

Groups of farmers mentioned several disease names with clinical features matching HPAI suspicion definition. Among these names, the term ห่า ('Ha') did not corre- spond to any defined avian pathogen. It is most likely a generic term used by farmers to describe any syndrome with extremely high mortality in a limited period of time which might be caused either by a Newcastle disease virus, HPAI or Fowl Cholera.

Information flows on disease outbreaks are difficult to capture. Contrary to animal sales or purchases, a central topic in veterinary epidemiology (Fournie et al., 2013; Rasamoelina-Andriamanivo et al., 2014), records of poultry health information exchanges linked to social contacts are dubious. High recall bias probability may limit the validity of the data collected. To overcome this risk of bias, rather than asking the participants to remember their past information exchanges, we asked them which information flows they perceived as relevant when faced to disease suspicion, based both on their past experience and their priorities in disease management.

For qualitative investigations, visualization tools of participatory epidemiology (Catley et al., 2012) enabled to reveal decision-making factors that were not expressed by participants in the first place. These tools were well understood by participants. Snowball sampling (Sadler et al., 2010) enabled to capture the diversity of actors impacted by surveillance systems and to confront their opinions on factors impacting disease reporting, such as sale of sick chickens, potential conflicts with cockfighting practitioners.

Previous studies based on participatory or anthropological investigations identified several factors of under-reporting of disease suspicions to public surveillance systems (Elbers et al., 2010a; Bronner et al., 2014; Fearnley, 2011) including lack of trust in veterinary authorities or differing risk perception. In the present study, the inadequacy between initial disease control policies and specific poultry farming practices was a critical obstacle to disease reporting. Native chicken farmers' priority to protect valuable 
animals and sustain cockfighting activities contradicted the HPAI control policies which mainly aimed at eradicating infection through culling and restriction on animal transport. These contradicting interests were already observed at the level of national policymakers (Safman, 2009). The defiance of cockfighting practitioners towards HPAI surveillance was also documented by an in-depth anthropological study (Paul et al., 2015). In the present study, presence of cockfighting activities in the area was presented as a major cause of HPAI suspicion under-reporting by both private and public actors. In the same time, the quality orientation of the native chicken meat trade had a positive impact on reporting. Native chicken farmers facing high mortality diseases could not sell their animals. In other areas and production types, other studies showed the sale of infected animals was a preferred alternative to disease reporting (Delabouglise et al., 2015a).

Information exchanges on disease suspicions are shaped by village homophily. The information is mainly shared in the same village for obvious reasons: poultry farmers who are neighbours of infected farms are more at risk of having their flock contaminated and must be informed in priority. Poultry farmers of the same village also have a higher probability of belonging to the same family and developing social ties with each other.

Results demonstrate that cockfighting practitioners facilitate the spatial diffusion of information beyond the village. Cockfighting practitioners gather significantly more information than other poultry farmers when accounting for the effect of village localization. This role of cockfighting practitioners in the network has two explanations. Cockfighting games create opportunities for developing social bounds between chicken farmers, which may increase the number of farmers each person might contact in case of disease suspicion (Paul et al., 2015). Secondly, cockfighting participants also own the most valuable animals, that is cocks with fighting experience. Protecting these praised animals might, in such case, be perceived as a priority by the owner and by his friends or members of his cockfighting team. Little information was shared in the purpose of getting support for disease management. The dominant purpose was warning each other to protect animals.

Infectious diseases with high potential of spread from one farm to another involve different types of collective management that can emerge independently of public stakeholders and can represent a substitute to public surveillance systems (Desvaux and Figuie, 2011). Some of these informal types of disease management can involve cooperation beyond the local scale of the household or the village. Informal information networks get more and more recognition by public stakeholders and can significantly contribute to surveillance efficiency (Davies, 2012). In the commercial farming systems in Vietnam, it was found that information networks beyond the village scale were mainly mediated by private suppliers of veterinary services (such as veterinary shops, agro-industrial companies, feed sellers) (Delabouglise et al., 2015b). In the case of native chicken farmers of Thailand presented hereby, the developed networks are related to a recreational activity.

\section{Conclusion}

The present study identified some characteristics of native chicken farming in Thailand that influence the acceptability of surveillance, that is social importance of cockfighting and quality-oriented value chain. It also demonstrates that cockfighting practitioners play a key role in the informal dissemination of HPAI suspicion information. Cockfighting practitioners place a high value in cocks, which affects both the structure of the disease information flows network and their relation to the official HPAI surveillance system.

\section{Acknowledgement}

The study was funded by the French Agency for Development (AFD) and conducted by CIRAD (Centre of International Agriculture Research for Development) in the framework of the REVASIA project. The authors are grateful to the Department of Livestock Development (DLD) of Thailand, the provincial veterinary office of Sukhothai and the district veterinary office of Kong Krailat for their support. They also thank all the interviewed villagers for their participation in the study and the translators Ms Thitiya Seekhasamban and Mr Panupang Junfeung for their commitment in the research activities.

\section{References}

Anderson, M. J., and P. Legendre, 1999: An empirical comparison of permutation methods for tests of partial regression coefficients in a linear model. J. Statist. Comput. Sim. 62, 271303.

Auewarakul, P., W. Hanchaoworakul, and K. Ungchusak, 2008: Institutional responses to avian influenza in Thailand: Control of outbreaks in poultry and preparedness in the case of human-to-human transmission. Anthropol. Med. 15, 61-67.

Ballings, M., and D. Van den Poel, 2013: AUC: Threshold independent performance measures for probabilistic classifiers. $\mathrm{R}$ package version 0.3.0. Available at: http://finzi.psych.upenn.edu/library/AUC/html/00Index.html (accessed January 13 2015).

Bonacich, P., and P. Lloyd, 2001: Eigenvector-like measures of centrality for asymmetric relations. Soc. Networks 23, 191-201.

Bonfoh, B., K. Schwabenbauer, D. Wallinga, J. Hartung, E. Schelling, J. Zinsstag, F.-X. Meslin, R. Tschopp, J. A. Akakpo, 
and M. Tanner, 2010: Human Health Hazards Associated with Livestock Production. In: Steinfeld, H., H. A. Mooney, F. Schneider, and L. E. Neveille (eds), Livestock in a Changing Landscape: Drivers, Consequences and Responses, pp. 197219. Island Press, Washington, DC.

Bowen, G. A., 2008: Naturalistic inquiry and the saturation concept: a research note. Qual. Res. 8, 137-152.

Bronner, A., V. Henaux, N. Fortane, P. Hendrikx, and D. Calavas, 2014: Why do farmers and veterinarians not report all bovine abortions, as requested by the clinical brucellosis surveillance system in France? BMC Vet. Res. 10, 93.

Butts, C. T., 2010: sna: Tools for Social Network Analysis. Available at: http://cran.r-project.org/web/packages/sna/index.html (accessed November 10 2012).

Catley, A., R. G. Alders, and J. L. Wood, 2012: Participatory epidemiology: approaches, methods, experiences. Vet. J. 191, 151-160.

Chilonda, P., and G. Van Huylenbroeck, 2001: A conceptual framework for the economic analysis of factors influencing decision-making of small-scale farmers in animal health management. Rev. Sci. Tech. 20, 687-700.

Csardi, G., and T. Nepusz, 2006: The igraph software package for complex network research. Available at: http://igraph.org (accessed November 10 2012).

Davies, S., 2012: Nowhere to hide: informal disease surveillance networks tracing state behaviour. Glob. Change, Peace Secur. 24, 95-107.

Dekker, D., D. Krackhardt, and T. Snijders, 2003: Multicollinearity Robust QAP for Multiple-Regression. Available at: http:// www.casos.cs.cmu.edu/publications/papers/dekker_2003_multicollinearity.pdf (accessed January 21 2015).

Delabouglise, A., T. H. Dao, D. B. Truong, T. T. Nguyen, N. T. Nguyen, R. Duboz, G. Fournie, N. Antoine-Moussiaux, V. Grosbois, D. T. Vu, T. H. Le, V. K. Nguyen, G. Salem, and M. Peyre, 2015a: When private actors matter: Information-sharing network and surveillance of Highly Pathogenic Avian Influenza in Vietnam. Acta Trop. 147, 38-44.

Delabouglise, A., N. Antoine-Moussiaux, D. T. Phan, C. D. Dao, T. T. Nguyen, D. B. Truong, N. T. X. Nguyen, D. T. Vu, V. K. Nguyen, T. H. Le, G. Salem, and M. Peyre, 2015b: The perceived value of passive animal health surveillance: The case of Highly Pathogenic Avian Influenza in Vietnam. Zoonoses Public Health 63, 112-128.

Desvaux, S., and M. Figuie, 2011: Formal and informal surveillance systems. How to build bridges? Bulletin de l'AEEMA 59 60, 352-355.

Elbers, A. R., M. J. Gorgievski-Duijvesteijn, P. G. van der Velden, W. L. Loeffen, and K. Zarafshani, 2010a: A socio-psychological investigation into limitations and incentives concerning reporting a clinically suspect situation aimed at improving early detection of classical swine fever outbreaks. Vet. Microbiol. 142, 108-118.

Elbers, A. R., M. J. Gorgievski-Duijvesteijn, K. Zarafshani, and G. Koch, 2010b: To report or not to report: a psychosocial investigation aimed at improving early detection of avian influenza outbreaks. Rev. Sci. Tech. 29, 435-449.

FAO, 2014: EMPRES-I, Global Animal Disease Information System. Available at: http://empres-i.fao.org/eipws3g/ (accessed May 5 2015).

Fearnley, L., 2011: Disputing Efficacy: Poultry Farmers and Pharmaceutical Exchange in Nanchang County, Jiangxi. 3rd International Workshop on Community-based Data Synthesis, Analysis and Modeling of Highly Pathogenic Avian Influenza H5N1 in Asia. Beijing, China.

Fournie, G., J. Guitian, S. Desvaux, V. C. Cuong, H. Dung do, D. U. Pfeiffer, P. Mangtani, and A. C. Ghani, 2013: Interventions for avian influenza A (H5N1) risk management in live bird market networks. Proc. Natl. Acad. Sci. U. S. A., 110, 9177-9182.

Gilbert, M., X. M. Xiao, P. Chaitaweesub, W. Kalpravidh, S. Premashthira, S. Boles, and J. Slingenbergh, 2007: Avian influenza, domestic ducks and rice agriculture in Thailand. Agr.

Ecosyst. Environ. 119, 409-415.

Government of Thailand, 2007: The Second National Strategic Plan for Prevention and Control of Avian Influenza and Preparedness for Influenza Pandemic. The Veterans Press, Bangkok, Thailand.

Graneheim, U. H., and B. Lundman, 2004: Qualitative content analysis in nursing research: concepts, procedures and measures to achieve trustworthiness. Nurse Educ. Today 24, 105112.

Heft-Neal, S., J. Otte, W. Pupphavessa, D. Roland-Holst, S. Sudsawasd, and D. Zilberman, 2008: Supply Chain Auditing for Poultry Production in Thailand. Available at: http://www.fao.org/ag/againfo/programmes/en/pplpi/docarc/rep-0809_thaipoultrychain.pdf (accessed January 11 2013).

Heft-Neal, S., F. Kahrl, J. Otte, and D. Roland-Holst, 2009a: Assessment of Smallholder Indigenous Poultry Producer Viability in Thailand. Available at: http://r4d.dfid.gov.uk/Output/ 180392/ (accessed February 11 2013).

Heft-Neal, S., F. Kahrl, J. Otte, and D. Roland-Holst, 2009b: HPAI Risk Reduction and Smallholder Poultry Supply Chains - The Case of Thailand. Available at: http://r4d.dfid.gov.uk/ Output/180394/ (accessed January 11 2013).

Hickler, B., 2007: Bridging the gap between HPAI "awareness" and practice in Cambodia. Recommendations from an Anthropological Participatory Assessment. Report to the Food and Agriculture Organisation, Rome.

Hoinville, L., 2011: Animal Health Surveillance Terminology. Final Report from Pre-ICAHS Workshop. Available at: http:// www.fp7-risksur.eu/sites/fp7-risksur.eu/files/partner_logos/ icahs-workshop-2011_surveillance_tewrminology_report_V1.2.pdf (accessed January 23 2014).

Hosmer, D. W., and S. Lemeshow, 2000: Applied Logistic Regression. John Wiley \& Sons, Hoboken, New Jersey.

Jackson, M. O., 2008: Social and Economic Networks. Princeton University Press, New Jersey. 
Paradis, E., J. Claude, and K. Strimmer, 2004: APE: analyses of phylogenetics and evolution in R language. Bioinformatics 20, 289-290.

Paul, M., S. Tavornpanich, D. Abrial, P. Gasqui, M. CharrasGarrido, W. Thanapongtharm, X. M. Xiao, M. Gilbert, F. Roger, and C. Ducrot, 2010: Anthropogenic factors and the risk of highly pathogenic avian influenza $\mathrm{H} 5 \mathrm{~N} 1$ : prospects from a spatial-based model. Vet. Res. 41, 28.

Paul, M., S. Wongnarkpet, P. Gasqui, C. Poolkhet, S. Thongratsakul, C. Ducrot, and F. Roger, 2011: Risk factors for highly pathogenic avian influenza (HPAI) H5N1 infection in backyard chicken farms. Thailand. Acta Trop. 118, 209-216.

Paul, M., V. Baritaux, S. Wongnarkpet, C. Poolkhet, W. Thanapongtharm, F. Roger, P. Bonnet, and C. Ducrot, 2013: Practices associated with Highly Pathogenic Avian Influenza spread in traditional poultry marketing chains: Social and economic perspectives. Acta Trop. 126, 43-53.

Paul, M. C., M. Figuie, A. Kovitvadhi, S. Valeix, S. Wongnarkpet, C. Poolkhet, S. Kasemsuwan, C. Ducrot, F. Roger, and A. Binot, 2015: Collective resistance to HPAI H5N1 surveillance in the Thai cockfighting community: Insights from a social anthropology study. Prev. Vet. Med. 120, 106-114.

R core team, 2014: R: a language and environment for statistical computing. Available at: http://www.R-project.org/ (accessed October 8 2012).

Rasamoelina-Andriamanivo, H., R. Duboz, R. Lancelot, O. F. Maminiaina, M. Jourdan, T. M. Rakotondramaro, S. N. Rakotonjanahary, R. S. de Almeida, B. Durand. Rakotondravao, and V. Chevalier, 2014: Description and analysis of the poultry trading network in the Lake Alaotra region, Madagascar: Implications for the surveillance and control of Newcastle disease. Acta Trop. 135, 10-18.
Rushton, J., R. Viscarra, E. Guerne Bleich, and A. McLeod, 2005: Impact of avian influenza outbreaks in the poultry sectors of five South East Asian countries (Cambodia, Indonesia, Lao PDR, Thailand, Viet Nam) outbreak costs, responses and potential long term control. World Poultry Sci. J. 61, doi:10.1079/WPS200570.

Ryu, H. M., M. A. Woo, K. Lee, and J. K. Yoo, 2013: Permutation predictor tests in linear regression. Commun. Korean Stat. Soc. 20, 147-155.

Sadler, G. R., H. C. Lee, R. S. Lim, and J. Fullerton, 2010: Recruitment of hard-to-reach population subgroups via adaptations of the snowball sampling strategy. Nurs. Health Sci. 12, 369-374.

Safman, R., 2009: The Political Economy of Avian Influenza in Thailand. STEPS Working Paper. STEPS center, Brighton, United Kingdom.

Scoones, I., and P. Forster, 2008: The International Response to Highly Pathogenic Avian Influenza: Science, Policy and Politics. STEPS Working Paper. STEPS center, Brighton, United Kingdom.

Venables, W. N., and B. D. Ripley, 2002: Modern Applied Statistics with S. 4thEdition. Springer, New York.

Walker, P., S. Cauchemez, N. Hartemink, T. Tiensin, and A. C. Ghani, 2012: Outbreaks of H5N1 in poultry in Thailand: the relative role of poultry production types in sustaining transmission and the impact of active surveillance in control. J. $R$. Soc. Interface 9, 1836-1845.

World Health Organization, 2014: Cumulative number of confirmed human cases of avian influenza $\mathrm{A}(\mathrm{H} 5 \mathrm{~N} 1)$ reported to WHO. Available at: http://www.who.int/influenza/human_animal_interface/H5N1_cumulative_table_archives/en/ (accessed July 232014 ). 